\title{
Neuroticism and Academic Achievement Motivation in Adolescent
}

\author{
Balvant M. Chhansiya ${ }^{1}$, Yogesh A. Jogsan ${ }^{2}$
}

\section{ABSTRACT}

The main purpose of this research was to find out the mean difference in adolescents. The total 80 adolescents as a variation belonging to adolescents were taken. The research tool for neuroticism Mosley personality scale was measured by Isenk and tool for academic achievement motivation were used which made by T.R.Sharma. Here t-test was applied to check the significant of in neuroticism and academic achievement motivation between male and female adolescents.

The study revealed that there was no significant difference between male and female adolescent in neuroticism. There was no significant difference between male and female adolescent in academic achievement motivation.

Keywords: Neuroticism and Academic Achievement Motivation

Neuroticism is a fundamental personality trait in the study of psychology characterized by anxiety, moodiness, worry, envy, and jealousy. Individuals who score high on neuroticism are more likely than the average to experience such feelings as anxiety, anger, envy, guilt, and depressed mood. They respond more poorly to stressors, are more likely to interpret ordinary situations as threatening, and minor frustrations as hopelessly difficult. They are often selfconscious and shy, and they may have trouble controlling urges and delaying gratification. Neuroticism is a risk factor for the "internalizing" mental disorders such as phobia, depression, panic disorder, and other anxiety disorders, all of which are traditionally called neuroses.

Neuroticism appears to be related to physiological differences in the brain. Hans Eysenck theorized that neuroticism is a function of activity in the limbic system, and his research suggests that people who score highly on measures of neuroticism have a more reactive sympathetic nervous system, and are more sensitive to environmental stimulation. Behavioral genetics researchers have found that a significant portion of the variability on measures of neuroticism can be attributed to genetic factors.

\footnotetext{
${ }^{1}$ Department of Psychology, Suarashtra University, Rajkot

${ }^{2}$ Department of Psychology, Suarashtra University, Rajkot, Editor, IJIP
} 
Neuroticism is operationally defined by items referring to irritability, anger, sadness, anxiety, worry, hostility, selfconsciousness, and vulnerability that have been found to be substantially correlated with one another in factor analyses (Costa \& McCrae, 1992a; Goldberg, 1993). For individuals who are high on neuroticism, such negative emotional responses to challenges are both frequent and out of proportion to the circumstances (McCrae \& Costa, 2003). In addition, persons high in neuroticism are often self-critical, sensitive to the criticism of others, and feel personally inadequate (Watson, Clark, \& Harkness, 1994). The dimension of neuroticism, also often referred to as negative emotionality or negative affectivity, is included in nearly all major models of personality traits (Matthews, Deary, \& Whiteman, 2003), including three-factor (Eysenck, 1947; Tellegen, 1982) and five-factor models (Costa \& McCrae, 1992b; Goldberg, 1993; Zuckerman, Kuhlman, Teta, Joireman, \& Kraft, 1993).

Although the stability of neuroticism, in the sense of maintaining rank-order position relative to other persons, increases with age from adolescence through adulthood (Roberts \& DelVecchio, 2000), mean neuroticism scores peak in late adolescence and decline moderately through adulthood (Costa et al., 1986; McCrae et al., 2002; Roberts \& Mroczek, 2008). Mean neuroticism scores of females are slightly but significantly higher than for males (Costa, Terracciano, \& McCrae, 2001) and neuroticism scores tend to be somewhat higher among individuals with lower socioeconomic status (Judge, Higgins, Thoresen, \& Barrick, 1999). Therefore, it is informative that most studies of the associations between neuroticism and mental and physical health that controlled age, sex, and socioeconomic status have found that neuroticism is associated with mental and physical health independent of its correlation with these demographic factors (Kendler, Kuhn, \& Prescott, 2004; Neeleman, Ormel, \& Bijl, 2001; Stronks, van de Mheen, Looman, \& Mackenbach, 1997).

Neuroticism can be viewed as a heterogeneous trait consisting of multiple facets that are highly correlated but partially distinct, including anger, sadness, anxiety, worry, and hostility (Weiss \& Costa, 2005). Indeed, many studies of the relation between negative affectivity and adverse outcomes focus on fine-grained traits that might be considered facets of neuroticism, such as trait hostility and anger (T. W. Smith, Glazer, Ruiz, \& Gallo, 2004; Suarez, Lewis, \& Kuhn, 2002). The present paper focuses on the broad trait of neuroticism, but some facets of neuroticism may be more important than others for specific purposes. It should be emphasized that there is a lack of full independence between most measures of neuroticism and measures of some mental health outcomes. In particular, the fact that some of the items that define neuroticism in most scales overlap with symptoms of depression and anxiety complicates the interpretation of correlations with these disorders (Jylha \& Isometsa, 2006). In particular, in cross-sectional studies, it is possible that neuroticism and mental disorders could be correlated because persons who are currently experiencing an episode of depression or anxiety disorder might endorse more of these overlapping neuroticism items than either before or after the episode. Nonetheless, the association between neuroticism and public health outcomes is not merely an artifact of overlapping criteria. A number of longitudinal studies have controlled for shared items and 
concurrent depressive states and still found significant associations between the construct of neuroticism and measures of depression (Fergusson, Horwood, \& Lawton, 1989; Schmutte \& Ryff, 1997; Spijker, de Graaf, Oldehinkel, Nolen, \& Ormel, 2007). In addition, as summarized in this paper, neuroticism is robustly linked to many mental disorders (e.g., somatoform disorders, eating disorders, schizophrenia, and substance use disorders) and to physical health problems that are not defined by symptoms that overlap with neuroticism items. Indeed, there is some evidence that neuroticism may predict a wide range of physical health problems even when depression is controlled (Bouhuys, Flentge, Oldehinkel, \& van den Berg, 2004; Russo, Katon, Lin, \& Von Korff, 1997). Nonetheless, greater attention to the issues of conceptual and criterion overlap in the operational definitions of neuroticism and some mental disorders is needed in the future.

The term "need for achievement" was used for the first time and introduced into psychology by H. Murray in Explorations in Personality (1938). The author defined it as an intense prolonged and repeated efforts to accomplish something difficult; to work with singleness of purpose towards a high and distant goal; to have the determination to win” [7, p.164]. Murray with Ch. Morgan developed also Thematic Apperception Test (TAT) which is widely used to support assessment of needs and motives. Thereafter, research on achievement motivation was extended by D. McClelland According to him, the achievement motivation is a constant drive to improve one's level of performance, to accomplish success in contention. The author also claimed that need for achievement is the result of emotional conflict between the hope to approach success and the desire to avoid failure (Steinmayr, Spinath, 2009)

Academic achievement or (academic) performance is the outcome of education the extent to which a student, teacher or institution has achieved their educational goals. Academic achievement is commonly measured by examinations or continuous assessment but there is no general agreement on how it is best tested or which aspects are most important procedural knowledge such as skills or declarative knowledge such as facts.

Need for achievement was one of the first social motives to be studied in detail (McClelland et al., 1953), and research into this motive continues even today (Spence, 1989). As characterized by D.C. McClelland and J.W. Atkinson, "the need for achievement (n-ach) is the desire to compete with a standard of excellence." The concept of achievement motivation has been developed by McClelland, Atkinson, Clark and Lowell (1953). They defined this concept as a "concern over competition with standards of better than someone else.

Atkinson (1958) came to the conclusion that there is need for achievement in an individual. According to Atkinson and Feather (1966), "The achievement motives is conceived as a latest disposition which is manifested in overt striving only when the individual perceives performance as instrumental to a sense of personal accomplishment.” People in whom need for achievement is strong, seek to become accomplished, and to improve their task performance. They are taskoriented and prefer to work on tasks that are challenging and on which their performance can be evaluated in some way, either by comparing it with other people's performance or in terms of 
some other standards, "Achievement is task-oriented behaviour that allows the individual's performance to be evaluated according to some internally or externally imposed criterion, that involves the individual in competing with others, or that otherwise involves some standards of excellence" (Smith, 1997; Spence and Helmreich, 1983). Achievement motivation can be seen in many areas of human behaviour, on the job, in homemaking, or athletic competition. Andrews (1967) and Raynor (1970) stated that an individual who have high in achievement motivation tend to get higher grades in school, earn more rapid promotions, and attain greater success in running their own businesses than persons low in such motivation Therefore achievement motivation has been considered as an important concept in the dynamics of human behaviour. Tripathi (2004) concluded that motivation is positively associated with academic achievement. The motivation applied for achieving academic objective is termed as academic achievement motivation.

Jiyoung Park (2012) Clarifying the links between social support and health: Culture, stress, and neuroticism matter. Japanese and US adults found significant associations between perceived support and health. The association was more strongly evident among Japanese (from a supportapproving cultural context) who reported high life stress (in a support requiring situation). Moreover, the link between support and health was especially pronounced if these Japanese were low in neuroticism.

Brinda B. Sharma (2013) Gender Differences in Adolescent Neuroticism. Findings of the study revealed significant correlation of both the variables on neuroticism in adolescents. The correlation was negative for a cordial level of parent child relationship and positive for the remaining variable. Gender differences were noted in the degree of neuroticism as well as in appraisal of self and stress tolerance in interpersonal relations.

Sunita Badola (2013) Effect of School's on Academic Achievement Motivation Of Secondary level Students. Results showed that there was significant difference among Government, Public and convent School Secondary Students on their academic achievement motivation. The mean difference was found significant on male and female as well as Urban and Rural Secondary School Students on their Academic Achievement Motivation. Insignificant difference was found between Public \& Convent school students on their academic achievement motivation.

Kamariah Abu Bakar (2010) Relationships between university students' achievement motivation, attitude and academic performance in Malaysia. Results indicated a positive significant correlation between students' attitude towards learning and achievement motivation $(\mathrm{r}=0.53, \mathrm{p}$ $<.001)$, and between students' attitude and academic achievement $(\mathrm{r}=0.16, \mathrm{p}<.001)$. However, a negative and low correlation $(\mathrm{r}=-.038, \mathrm{p}>.05)$ was observed between students' achievement motivation and their academic achievement.

RESEARCH PROBLEM:

"Neuroticism and academic achievement motivation in adolescent" 


\section{OBJECTIVES:}

The main objectives of study were as under.

1. To measure the neuroticism in adolescent.

2. To measure the academic achievement motivation in adolescent.

3. To measure the correlation between neuroticism and academic achievement motivation.

\section{HYPOTHESIS:}

To related objectives of this null hypothesis were as under.

1. There in no significant difference in neuroticism in adolescent.

2. There in no significant difference in academic achievement motivation in adolescent.

3. There is no correlation between neuroticism and academic achievement motivation.

\section{METHOD}

\section{Participants:}

According to the purpose of present study total 80 sample has been selected. There were 40 male adolescent and 40 female adolescent were taken as a sample from different area in Rajkot city. (Gujarat)

\section{Research design:}

The aim of present study was to a study of neuroticism and academic achievement motivation in adolescent. For these total 80 adolescent were taken as a sample. Here to the measure neuroticism in the Mosley personality scale was used, measured by Isenk and tool for academic achievement motivation were used which made by T.R.Sharma. To check difference between group t-test method was used. The result discussion of neuroticism and academic achievement motivation is as under.

\section{Tools:}

For this purpose the following test tools were considered with their reliability, validity and objectivity mentioned in their respective menus in present study two inventories is used.

Here to the measure neuroticism in the Mosley personality scale was used, measured by Isenk and tool for academic achievement motivation were used which made by T.R.Sharma.

\section{Procedure:}

According to purpose of present study for data collection the investigator explained the purpose the study to the subjects for these total 40 male and 40 female adolescent were taken as a sample from different part of Rajkot city (Gujarat). Testing was done personally with adolescent. The whole procedure of fill the inventory was explained to them fully and clearly. The instructions given on questionnaire were explained to them. It was also made clear to them that 
these scores would be kept secret. It was checked that non of the participants left any questions unanswered or that no participants encircled both the answer given against questions.

\section{RESULTS AND DISCUSSIONS}

The main objective of present study was to measure the "neuroticism and academic achievement motivation in adolescent." In it statistical t-test method is used. Result discussion of present study is as under.

Table-1

The table- 1 indicates that the mean score of neuroticism in male adolescent are 28.06 and female adolescent are 29.36 The standard deviations for both male and female adolescents are 4.27 and 4.37 respectively. The difference between these two means is not significant at 0.05 level of confidence as the value of t-test is 1.63 Findings shown that female adolescent are more affected by neuroticism in comparison to female adolescent. Female adolescent find themselves under more neuroticism because of their multiple roles. So the first hypothesis is accepted.

Evidences of research finding given by Jiyoung Park (2012) Clarifying the links between social support and health: Culture, stress, and neuroticism matter. Japanese and US adults found significant associations between perceived support and health. The association was more strongly evident among Japanese who reported high life stress. Moreover, the link between support and health was especially pronounced if these Japanese were low in neuroticism. Result was same as present study. There for we can say that present finding are supported by Jiyoung Park (2012). Also supported by Brinda B. Sharma (2013) reseach.

\section{Table-2}

The table- 2 indicates that the mean scores of academic achievement motivation in male adolescent and female adolescent are 27.06 and 28.03 the standard deviations for both male adolescent and female adolescent are 4.15 and 5.52 respectively. The difference between these two means is not significant at 0.05 level of confidence as the value of t-test is $0.77 \mathrm{~A}$ perusal of that reveals not significant difference between academic achievement motivations in the two groups. In this study female adolescent scored higher on academic achievement motivation in comparison to their male adolescent counterparts. It is not surprising because in our culture, society renders more care, protection and support to male adolescent. So the second hypothesis is also accepted.

Evidences of research finding given by Kamariah Abu Bakar (2010) Relationships between university students' achievement motivation, attitude and academic performance in Malaysia. Results indicated a and between students' attitude and academic achievement. However, a negative and low correlation was observed between students' achievement motivation and their academic achievement. Result was same as present study. There for we say 
that present finding are supported by Kamariah Abu Bakar (2010) and Sunita Badola (2013) research.

\section{CONCLUSION}

We can conclude by data analysis as follows;

There were not significant differences between the mean scores of two groups on neuroticism. Female adolescent are more affected by neuroticism in comparison to female adolescent and there were not significant difference between the mean scores of two groups on academic achievement motivation. Female adolescent scored higher on academic achievement motivation in comparison to their male adolescent counterparts.

\section{REFERENCES:}

Andrews, J.D.W., (1967). The Achievement Motivation and Achievement in two Types of Organization, Journal of Personality and social Psychology, 6,163-168,

Atkinson, J.W. and Feather, N.T. (Ed), (1966) A theory of Achievement Motivation, New York: wily.

Bouhuys AL, Flentge F, Oldehinkel AJ, van den Berg MD (2004) Potential psychosocial mechanisms linking depression to immune function in elderly subjects. Psychiatry Research. ;127:237-245.

Brinda B. Sharma (2013) Gender Differences in Adolescent Neuroticism. IOSR Journal Of Humanities And Social Science (IOSR-JHSS) Volume 9, Issue 5, PP 118-122

Costa PT, McCrae RR (1987) Neuroticism, somatic complaints and disease: Is the bark worse than the bite. Journal of Personality. 55:299-316.

Costa PT, McCrae RR (1992) Four ways five factors are basic. Personality and Individual Differences.13:653-665.

Costa PT, McCrae RR (1992) NEO five-factor inventory. Lutz, FL: Psychological Assessment Resources.

Costa PT, Terracciano A, McCrae RR (2001) Gender differences in personality traits across cultures: Robust and surprising findings. Journal of Personality and Social Psychology.81:322-331.

Eysenck HJ (2003) Dimensions of personality. New York: Praeger.

Goldberg LR (1993) The structure of phenotypic personality traits. American Psychologist. 48:26-34.

Goldberg LR (1993) The structure of phenotypic personality traits. American Psychologist. 48:26-34.

Hans Jürgen Eysenck and Michael W. Eysenck (1985). Personality and individual differences: A natural science approach. Perspectives on individual differences. Plenum Press (Springer). ISBN 0-306-41844-4.

J. W. Atkinson, ed., Motives in Fantasy, Action and Society. Princeton, N.J.: Van Nos -trand.

Jiyoung Park (2012) Clarifying the links between social support and health: Culture, stress, and neuroticism matter Journal of Health Psychology 18(2) 226-235

Jylha P, Isometsa E (2006) The relationship of neuroticism and extraversion to symptoms of anxiety and depression in the general population. Depression and Anxiety.;23:281-289. 
Kamariah Abu Bakar (2010) Relationships between university students' achievement motivation, attitude and academic performance in Malaysia Procedia - Social and Behavioral Sciences Volume 2, Issue 2,Pages 4906-4910

Kendler KS, Kuhn J, Prescott CA (2004) The interrelationship of neuroticism, sex, and stressful life events in the prediction of episodes of major depression. American Journal of Psychiatry. 161:631-636.

Matthews G, Deary IJ, Whiteman MC. Personality traits (2003) Cambridge, UK: Cambridge University Press.

McClelland, D.C. (1958). Methods of Measuring Human Motivation. In:

McCrae RR, Costa PT (1993) Personality in adulthood: A five-factor theory perspective. New York: Guilford Press.

McCrae RR, Costa PT (2003) Personality in adulthood: A five-factor theory perspective. New York: Guilford Press;

Meclelland, D.C., Atkison, J.W., Clark, R.A. and Lowell, E.L (1953) The Achievement Motivation, New York: Appleton-century-crofts.

Murray, H.A. (1938). Explorations in Personality. New York: Oxford University Press.

Neeleman J, Oldehinkel AJ, Ormel J (2003) Positive life change and remission of non-psychotic mental illness: A competing outcomes approach. Journal of Affective Disorders.76:69-78.

Raynor, J.O. (1970) Relating hips Between Achievement related Motives, Futare Orientations, and Academic Performance, 'Journal of personality and Social PsychalogyY, 15-28-33.

Roberts BW, DelVecchio WF (2000) The rank-order consistency of personality traits from childhood to old age: A quantitative review of longitudinal studies. Psychological Bulletin. 126:3-25.

Smith TW, MacKenzie J (2006) Personality and risk of physical illness. Annual Review of Clinical Psychology.2:435-467.

Spence, A.P. (1989). Biology of Ageing, Englewood cliffs, N.J. Prentice Hall.

Steinmayr, R., Spinath, B. (2009). The importance of motivation as a predictor of school achievement. Learning and Individual Differences, Vol. 19(1), 80-90.

Suarez EC, Lewis JG, Kuhn C (2006) The relation of aggression, hostility, and anger to lipopolysaccharide-stimulated tumor necrosis factor (TNF)- $\alpha$ by blood monocytes from normal men. Brain, Behavior, and Immunity.16:675-684.

Sunita Badola (2013) Effect of School's on Academic Achievement Motivation Of Secondary level Students Badola, S. / Educationia Confab ISSN: 2320-009X Vol. 2, No. 5

Tellegen A (1992) Brief manual for the Multidimensional Personality Questionnaire. Minneapolis: University of Minnesota

Tripathi, Kumar (2004) Effect of Achievement Motivation on Academic Achievement Indian, Educational Research Journal, Lucknow year 23, vol1.

Watson D, Clark LA, Harkness AR (1994) Structures of personality and their relevance to psychopathology. Journal of Abnormal Psychology.103:18-31.

Weiss A, Costa PT (2005) Domain and facet personality predictors of all-cause mortality among medicare patients aged 65 to 100. Psychosomatic Medicine. 67:724-733.

Zuckerman M, Kuhlman DM, Teta P, Joireman J, Kraft M (1993) A comparison of three structural models of personality: The big three, the big five, and the alternative five. Journal of Personality and Social Psychology.65:757-768. 